\title{
Investigation of the relationship between substance abuse, smoking, alcohol drinking and attempted suicide in children and adolescents
}

\author{
Hamid Reza Dehghan ${ }^{1}$, Fayegh Yousefi ${ }^{2}$, Soleiman Mohammadzadeh ${ }^{3}$ \\ 1- Resident of Psychiatry, Department of Psychiatry, Kurdistan University of Medical Sciences, Sanandaj, Iran. \\ 2- Associate Professor, Department of Psychiatry, Kurdistan University of Medical Sciences, Sanandaj, Iran. \\ 3- Assistant Professor, Department of Psychiatry, Kurdistan University of Medical Sciences, Sanandaj, Iran \\ (Corresponding Author). \\ E-mail: Dr.mohammadzadeh86@gmail.com
}

Received: 14/10/2020 Accepted: 19/12/2020

\begin{abstract}
Introduction: As one of the major public health concerns, the progressive increase in the suicide rate among children and adolescents is associated with biological, psychological and sociological aspects.

Aim: This study aimed investigating the demographic characteristics and the relationship between substance abuse, smoking and alcohol consumption by parents and children with suicide attempt history.

Method: The present case-control study was conducted on suicide attempters aged 6-18 years in 2019 in Sanandaj, Iran. The sampling method was random and based on the chronological order of referrals to hospitals. 44 individuals including 26 girls and 18 boys in the case group and 42 individuals in the control group were matched in terms of age, sex, and rural or urban residence. Data were collected using a self-made checklist and the BECK suicide questionnaire. Statistical data were analyzed by SPSS-22 software.

Results: The mean age of the subjects was 14.29 in the case group, and 13.5 years in the control group. Among suicide attempters, 13 were smokers, 12 were alcoholic consumers, and 7 were substance abusers. As opposed to the insignificant effect of maternal consumption of alcohol and substance, and smoking there were 28 smokers, 13 alcoholic consumers, and 10 substance abusers among fathers, indicating the significant role of fathers in the suicide attempts of children $(\mathrm{P}<0.05)$.
\end{abstract}

Conclusion: Due to the prevalence of suicide in Kurdistan and its concurrence with the use of drugs, cigarettes and alcohol, effective planning and intervention by policymakers and health and social authorities seem imperative.

Keywords: Suicide, Children, Adolescent, Cigarette smoking, Substance abuse, Alcohol drinking

How to cite this article: Dehghan HR, Yousefi F, Mohammadzadeh S. Investigation of the relationship between substance abuse, smoking, alcohol drinking and attempted suicide in children and adolescents. Shenakht Journal of Psychology and Psychiatry. $2021 ; 7$ (6): 1-11 .URL: http://shenakht.muk.ac.ir/article-1-926-en.pdf

Copyright $@ 2018$ the Author (s). Published by Kurdistan University of Medical Sciences. This is an open access article distributed under the terms of the Creative Commons Attribution-Non Commercial License 4.0 (CCBY-NC), where it is permissible to download, share, remix, transform, and buildup the work provided it is properly cited. The work cannot be used commercially without permission from the journal. 


\title{
بررسى رابطه مصرف مواد، سيگار و الكل در كودكان و نوجوانان اقدام كننده به خودكشى
}

\author{
حميد رضا دهقان'، فايق يوسفى '، سليمان محمد زادهَr

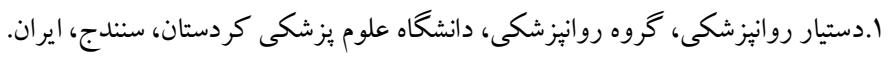

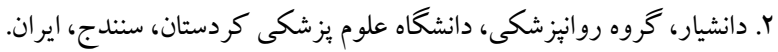

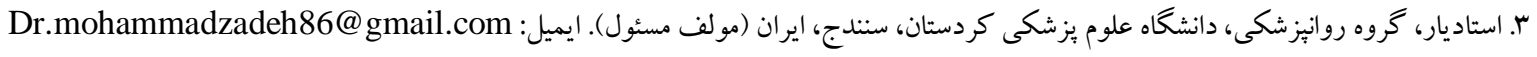

مقدمه: خودكشى كودكان و نوجوانان، از دغدغههاى حوزه سلامت بوده و سير صعودى آن حيطهاى بيولوزى، سايكولوزى و اجتماعى را در برمى گيرد. هدف: بررسى خصوصيات دمو گرافيكى و ارتباط مصرف مواد، سيگار و الكل توسط والدين و شخص با اقدام به خودكشى در گروه سنى 9 تا ل1 ال سال بود.

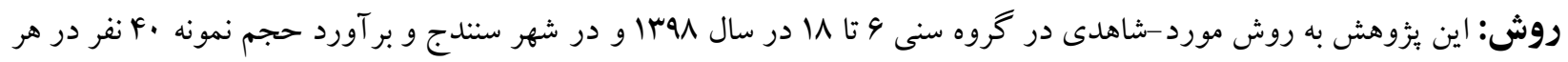

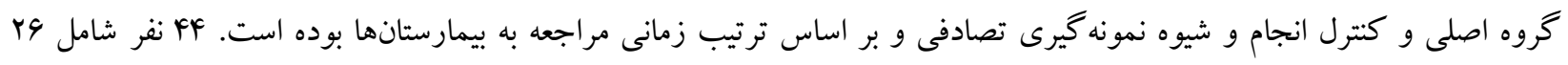

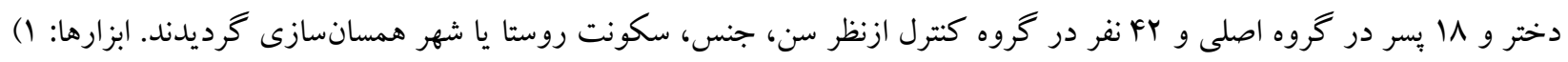

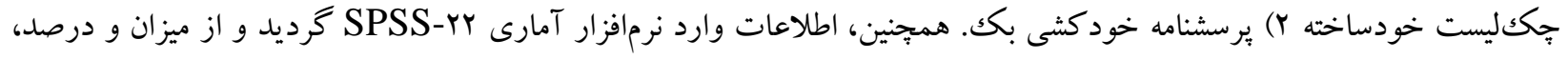
ميانخين و انحر اف استاندارد براى محاسبه اهداف توصيفى و از كاى سكوار براى تحليل اهداف تحليلى استفاده شد.

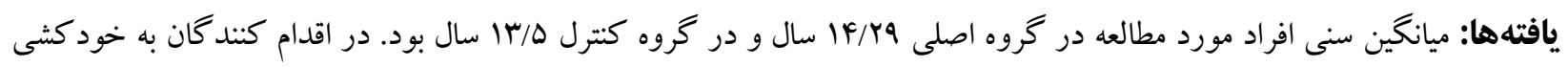

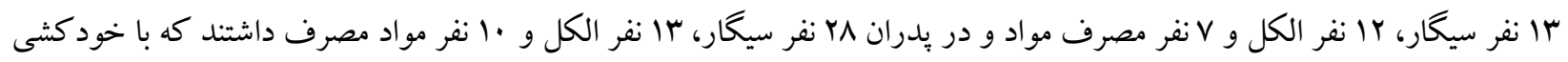

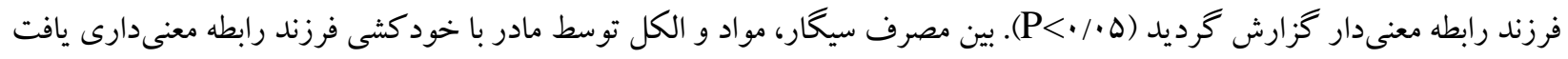

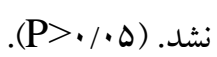
نتيجه كيرى: فراوانى اين مشكل در كردستان و همبودى با مصرف مواد، سيگار و الكل، برنامهريزى و مداخله سياست گذاران و مجريان سلامت و امور اجتماعى براى توقف سير صعودى رامى طلبد. كليدوازهها: خود كشى، كودك،، نوجوان، سيگار، مو اد، الكل 
يكى از جالشها در برداختن به خودكشى، شناسايى

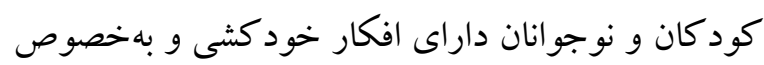
درمان آنهايى است كه اختلالات روانيز شكى رونى درمانشده دارند؛ زيرا همانطور كه خطر خودكشى موفق با افزايش سن بالا مىرود، ميزان شروع اختلال روانيزشكى درمان نشده نيز با افزايش سن كودكى و برد نوجوان بيشتر مىشود. كسانى كه جزو گروههاى برخطر هستند بايد تا زمانى كه ميل به خود كشى از بين برود، بسترى شوند. افراد در معرض خطر عبارت اند از: كسانى كه سابقه اقدام به خودكشى دارند (به خصوص با باد

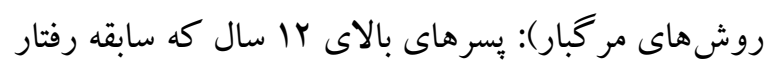
يرخاشگرانه يا سوء مصرف مواد دارند؛ استفاده از روش ترش

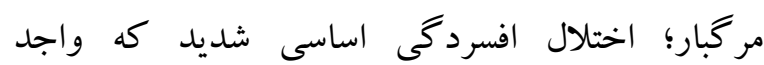
خصوصيات مردم گريزى، نوميدى و افكار خودكشى نرى مستمراست. با توجه به ماهيت هر دو رفتار، آسيب به خود و خودكشى كه به نوعى هدفمند مىباشند، سايكو ياتولوزى مشتر كى دارند، ازجمله اختلالات روانى، لهو افسردگى، تعارضات خانوادگى، غفلت، تروماها، اضطراب، سوء مصرف مواد، الكل، اختلال شخصيت

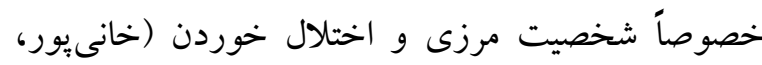
برجعلى و فسافى نزاد، هوسا ). واقعيت اين است كه افكار خودكشى در تمامى سنين وجود دارد، زنتيكك و داشتن سابقه خانوادكى رفتار خودكشى، عوامل بيولوزيك، دونى عوامل روانى - اجتماعى از قبيل احساس نااميدى، تكانش گرى،، مصرف مواد، سابقه رفتار برخاش گرايانه، در معرض تهاجم بودن، عوامل خطر خانوادگى براى رفتار

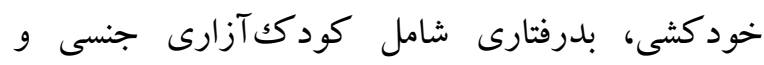

مقاله

خود كشى' عبارت است از هر گونه سعى و تلاش عامدانه و با آكاهى كامل فرد براى خاتمه زندگى به دلايل كوناگون زيستى، روانى و اجتماعى. خود كشى موفق در

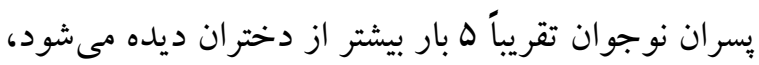
هرجند ميزان اقدام به خودكشى در دختران نوجوان س برابر بسران نوجوان است. فكر خود كشى يكك بديده ايستا

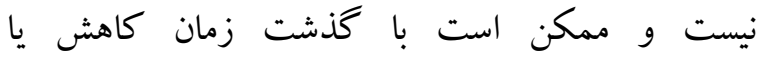
افزايشيابد. تصميم براى ارتكاب رفتار خود كشى ممكن است تكانشى و بدون دورانديشى كافى بوده و يا نتيجه نشخوار ذهنى طولانى باشد (سادوكى، سادو كك و روئيز '، .$(Y \cdot 10$ عوامل خطرساز اضافى در خودكشى عبارتاند از: سابقه خانوادكى رفتار انتحارى، قرار داشتن در معرض خشونت

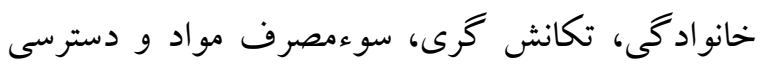
به روشهاى كشنده و در اين راستا خصوصيات مختلفى شامل احساس نوميدى، تكانش گرى، مصرف عود كننده مواد و سابقه رفتار برخاشخر انه با افزايش خطر خود كشى لهى ارتباط دارند. زندگى در خانهاى خشن و بدرفتار مى تواند طيف وسيعى از علائم آسيبهاى روانى ايجاد

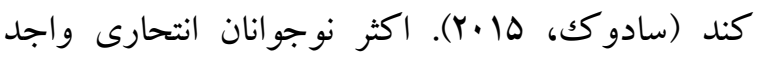
ملاككهاى تشخيصى يكى يا جند اختلال روانى هستند. مصرف الكل يا ساير مواد نيز ممكن است در نوجوانان آسيب بذير، زمينهساز رفتارهاى انتحارى باشد. در برخى موري موارد، نوجوانى كه يس از انجام رفتارى ممنوع، در انتظار مجازات از سوى يليس يا ساير منابع قدرت اقدام به خود كشى مى كند (سادو كى، ها •r). 
از نظر نويسندكان اين مبحث، از آنجا كه در برنامهريزىهاى يِشخيرى در مراقبتهاى سلامت، گروه سنى كودكك و نوجوان همواره به عنوان مهمترين گروه در نظر گرفته مىشود و به نظر مىرسد عوارض و عواقب روانشناختى، اقتصادى، فردى و اجتماعى اين مشكلات و

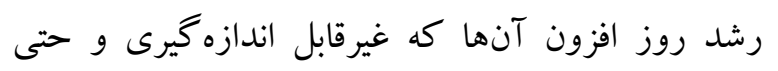
جبرانايذير است، مىتواند به عنوان يكى از بحرانهاى آينده در حوزه سلامت مطرح گردد و در اين راستا مصرف مواد و سيگار و الكل، يكى از عو امل زمينهساز و تداوم بخش اين معضل بوده و اهميت تدوين برنامههاى بيشگيرى كننده و نيز مداخلات بهموقع درمانى را آشكار مىسازد. اين امر از وظايف مسئولين امر سلامت بوده و عزم ملى فراكيرى را براى آن مى طلبد؛ لذا بررسى عوامل

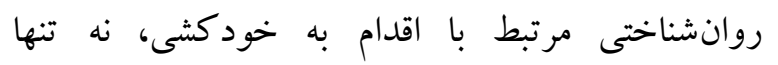
ضرورى، بلكه تا حدى اجتناب نايذير است. با توجه به آنجه اشاره شد، هدف از اين مطالعه بررسى خصوصيات

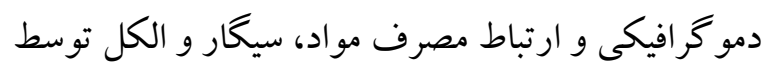
والدين و شخص با اقدام به خود كشى دركروه سنى 9 تا

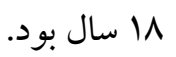

\section{روش}

يزوهش حاضر از نوع مطالعات مورد-شاهد و جامعه تحت مطالعه شامل كود كان و نوجوانان در گروه سنى 4

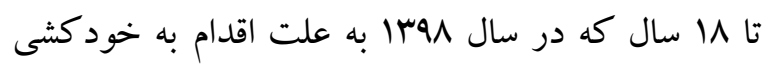
در اورزانسهاى بيمارستانهاى آموزشى درمانى سنندج مورد يذيرش قرار گرفنه، بوده است. نحوه انتخاب نمونهها

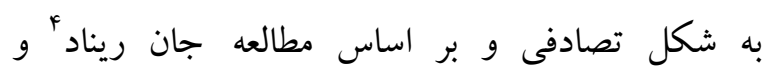

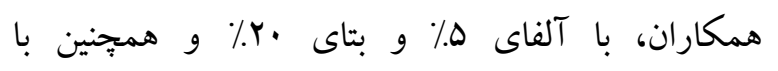

${ }^{4}$ - Johanne Renaud
جسمى و غفلت از مهمترين دلايل اين مشكل است

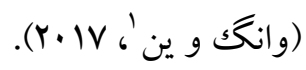
مطالعات نشان دادهاند كه سوءمصرف الكل، تنباكو و مواد مخدر، خطر خودكشى را در نوجوانان افزايش مىدهد. مصرف الكل در نوجوانى، بهخصوص شروع استفاده در بيش از نوجوانى، عامل خطر مهمى براى افكار خودكشى و اقدام به خودكشى در دختران و بِران نوجوان است (سيمبار، كلزار، عليزاده و حاجى فقاها، 94r). دريكك مطالعه مشخص شد كه مصرف الكل خطر خود كشى را در دختران نوجوان بَ برابر و در بسران IV ابرابر افزايش مىدهد. در نتايج بهدست آمده از مطالعهاى درباره عوامل خطر بر برك مرتبط با افكار و اقدام به خودكشى در •و ، نو جوان در جمهورى بنين، سوء مصرف الكل و مواد مخدر، با افزايش خطر و اقدام به خودكشى همراه بود (راندال،

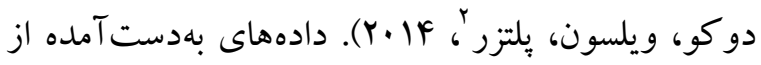

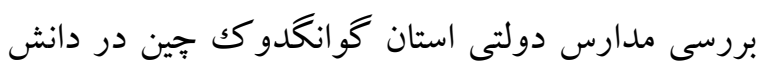
آموزان با تا 19 ساله نشان داد، استفاده از مواد مخدر و و آرامبخشها با نشانهاى افسردگى، كيفيت يائين خواب، صدمه عمدى به خود، افكار خودكشى و اقدام به خودكشى در هردو جنس در نوجوانان ارتباط مستقيم

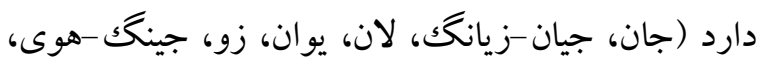

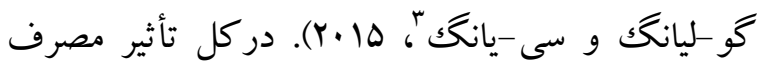
مواد در رفتارهاى منجر به خود كشى مشخص گرديده است و از اين نظر تفاوتى مابين دو جنس ملاحظه نشده

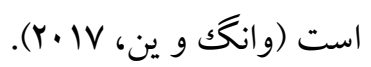

\footnotetext{
1- Wang, P.W. and Yen, C.F., 2017

${ }^{2}$ - Randall, J.R., Doku, D., Wilson, M.L. and Peltzer, K., 2014

${ }^{3}$ - Juan, W., Jian-Xiong, D., Lan, G., Yuan, H., Xue, G., Jing-Hui, H., Guo-Liang, H. and Ci-Yong, L., 2015
} 
تائيد و به بثزوهشخ ابلاغ گرديد. نمره دهى جك ليست بر اساس صفر و يكك بوده و براى تحليل مورد استفاده قرار گرفت.

يرسشنامه خودكشى استاندارد بك (بكى، كواكس و و

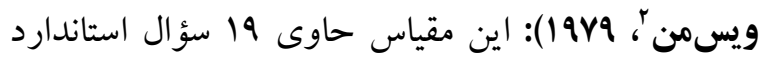
شده است كه توسط شركت كنند كان در مطالعه تكميل مى گردد. در اين مقياس، مواردى از قبيل آرزوى مركَ، تمايل به خودكشى به صورت فعال و غيرفعال، مدت و فراوانى افكار خودكشى، احساس كنترل بر خود، عوامل

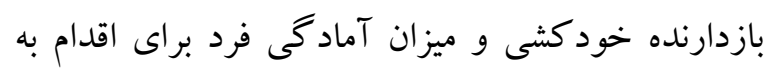
خود كشى را مورد سنجش قرارمىدهد. در اين برسشنامه هر يرسش داراى سه بِاسخ جداكانه است و نمره گذارى در هر يرسش از صفر تا دو است ينج سؤال اول غربالكرى بوده و در صورت فعال بودن خودكشى، برس، ليج جهارده سؤال بعدى تكميل مى گردد. اين مقياس داراى

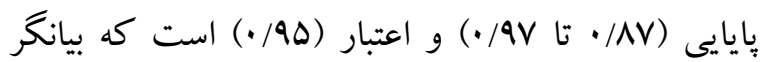
ارزش بالاى آن است. يايايى اين ابزار در مطالعه كلين و سورين در كشور آلمان در سال V.IV و نيز در سال ها +r در ايران توسط اصفهانى و همكاران مورد بررسى و و تائيد قرار گرفته است (اصفهانى، هاشمى و علوى، ها لـr؟ كليم، لومن، موبل و برهلر آ، Y. IV).

\section{يافته ها}

بر طبق معيارهاى ورود، كليه افراد در محدوده سنى 9 الى

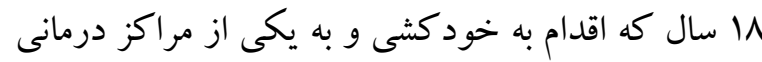
انتقال دادهشده بودند، مدنظر قرار خرفتند. در طول مدت جمع آورى نمونه، تعداد YM دختر و 19 يسر، جمعاً

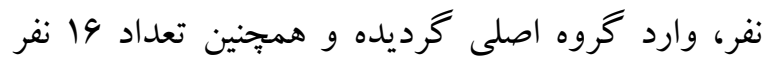

\footnotetext{
${ }^{2}$ - Beck suicidal Questionnaire (Beck, A.T., Kovacs, M. and Weissman, A., 1979)

${ }^{3}$ - Kliem, S., Lohmann, A., Mößle, T., \& Brähler, E., 2017
}

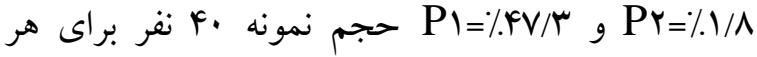
گروه و درمجموع ·^ نفر محاسبه گرديد. البته به خاطر احتمال ريزش نمونهها، تعداد 91 نفر تعيين شد كه درنهايت ه نفر ريزش داشته و تعداد 9م نفر وارد مطالعه

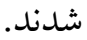

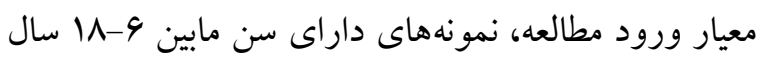
بدون تفكيك جنسيتى كه طى مدت مطالعه اقدام به خودكشى كردهاند و معيار خروج مطالعه، افرادى كه رضايت به شركت در مطالعه نداشتد، بوده است. بس از انجام مصاحبه و تكميل فرآيند بررسى در گروه مورد، بر مبناى سن، جنس، منطقه محل سكونت،

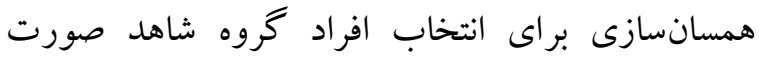
كرفت. يس از اخذ رضايتنامه كتبى از والدين و نيز كود كان و نوجوانان، اطلاعات دمو گرافيك ثبت گرديد. سبس مصاحبه روانيزشكى توسط رزيدنت آموزشديده، با فرد اقدام كننده ونيز حداقل يكى از والدين ايشان انجام و جکكليست خودساخته در ارتباط با خودكشى و برسشنامه خود كشى بك تكميل شد. همجِنين، اطلاعات وارد نرمافزار آمارى Yr SPSS كرديد و از ميزان و و درصد، ميانخين و انحراف استاندارد براى محاسبه اهداف توصيفى و از كاى سكوار براى تحليل اهداف تحليلى |ستفاده شد. جككليست خودساخته ارزيابع خودكشى!؛ اين جّك ليست حاوى گزينههايى براى اخذ اطلاعات مورد نياز بر اساس متغيرهاى مورد نياز بزوهش است كه توسط گروه يثزوهى شامل تعدادى از روانيزشكان و روانشناسان

\footnotetext{
${ }^{1}$ - Self-made checklist
} 
كنترل) براى گروه كنترل وارد مطالعه گرديدند. يافتهاى

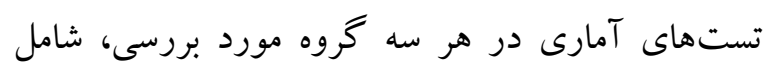

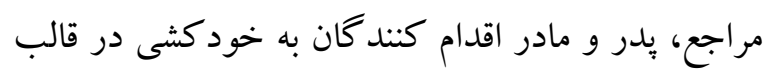
جدول ا ارائه گرديده است.
بسر و وץ نفر دختر در گروه كنترل با لحاظ همسانسازى

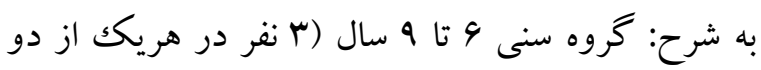

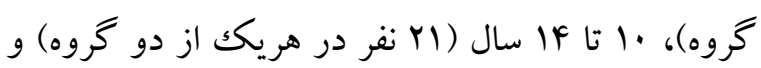

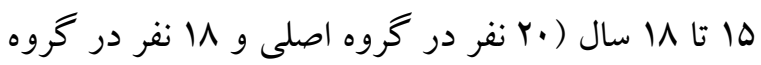

\begin{tabular}{|c|c|c|c|c|c|c|c|c|c|}
\hline \multicolumn{3}{|c|}{ مادر مراجع } & \multicolumn{3}{|c|}{ يدر مراجع } & \multicolumn{3}{|c|}{ مراجع } & \multirow[b]{2}{*}{ مصرف } \\
\hline ارزش p & شاهد & مورد & ارزش p & شاهد & مورد & ارزش p & شاهد & مورد & \\
\hline . & 1 & $r$ &.$/ \cdot 11$ & 19 & rA & $\% \cdot r$ & $r$ & Ir & سيعار \\
\hline . /194 & . & $r$ & $\cdot / 10 \mathrm{~V}$ & f & 9 & ./Iro & $r$ & $\wedge$ & قليان \\
\hline . /19Y & ${ }^{\circ}$ & $r$ & $\cdot / \cdot 1$ & $r$ & ir & $\cdot / \cdot \Delta$ & $r$ & Ir & الكل \\
\hline$\cdot / 19$ & . & r & .1 .19 & $r$ & 1. & $\cdot / \cdot v$ & . & v & مواد \\
\hline
\end{tabular}

نخرديد (P>/ه). در مورد مصرف قليان در گروه

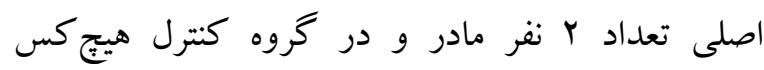
مصرف نداشت و P P P P معنىدار نغرديد (P>/A (P). در مورد مصرف الكل در گروه اصلى تعداد

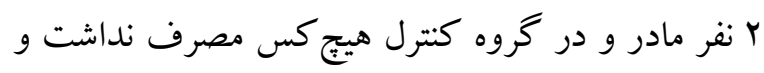
P=•//9Y و معنى P

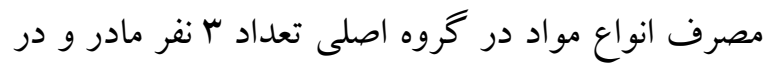
كروه كنترل كسى مصرف مواد نداشت و P P و

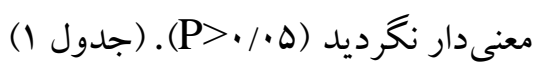
مصرف در مراجع:

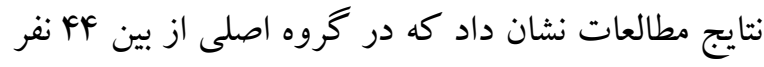

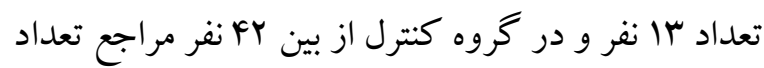

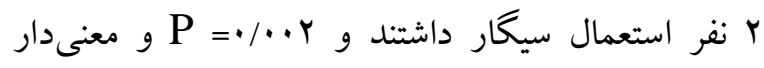

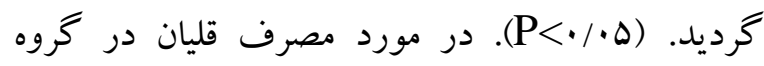
اصلى تعداد 1 نفر و در گروه كنترل ب نفر مصرف قليليان

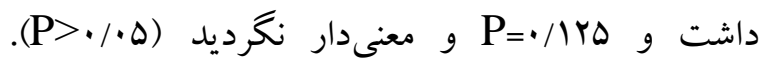
همجِنين در گروه اصلى تعداد rا نفر و در گروه كنترل

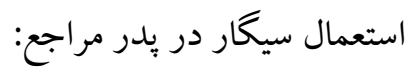

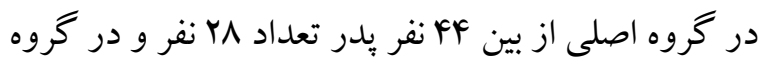

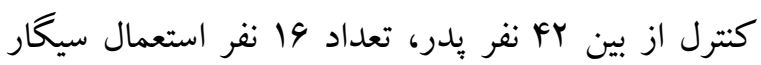

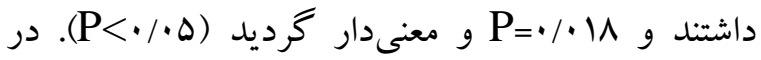
مورد مصرف قليان در گروه اصلى تعداد ه نفر و در گروه

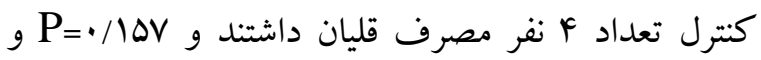

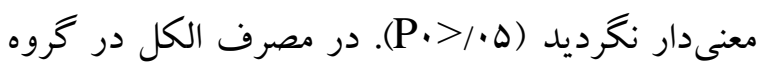
اصلى تعداد با نفر و در گروه كنترل تعداد ب نفر مصرف

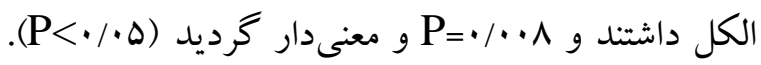
مصرف مواد در گروه اصلى تعداد لا نفر و در گروه كنترل تعداد ب نفر يدر مصرف انواع مختلفى از مواد

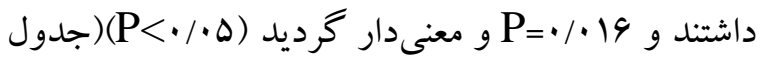

مصرف در مادر مراجع: - ماتج

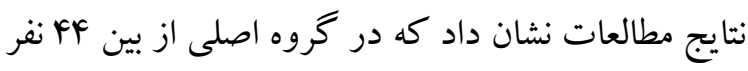
مادر تعداد r نفر و در گروه كنترل از بين rא نفر مادر

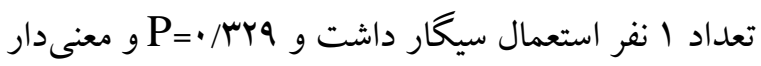


از نظر خصوصيات دمو گرافيكى در اين مطالعه تركيب

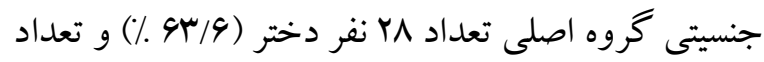
19 نفر يسر (\&/\&

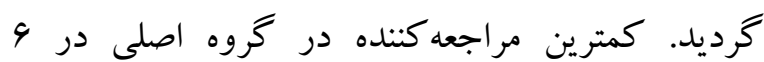
سالكى بوده است. مجموعاً م نفر از افراد اقدام كننده خود كشى موفق داشتند كه خانو اده ا نفر رضايت به ورود

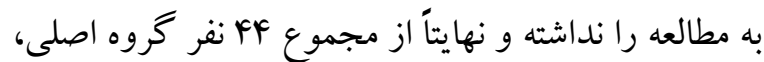
r نفر فوت كرديدهاند. در تركيب سنى اولين اقدام به

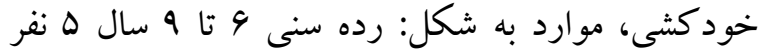

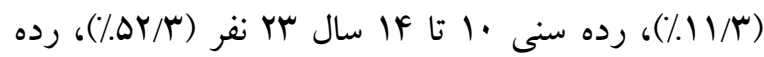
سنى ها تا 11 سال 19 نفر (4/4/\%) ثبت كرديدند؛

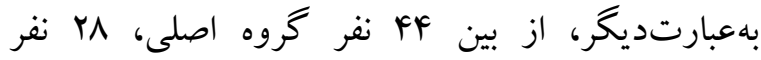

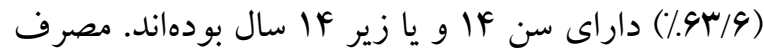
سيگار در بين بدران خانو اده در گروههاى اصلى و كنترل به ترتيب Y ن نفر (1/ رابطه معنىدارى با خودكشى فرزند داشته است.

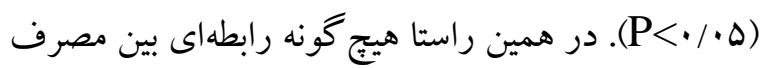
قليان توسط پِدر خانو اده و اقدام به خود كشى يافت نشد. در اين مطالعه، مصرف الكل در بين پيدران خانواده در

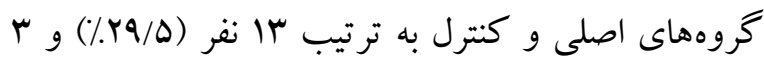
نفر (V) در آناليز رابطه معنىدارى با خود كشى فرزند داشته است. (ه•/ P<)؛ كه مشابه به نتايج برخى از مطالعات در ساير كشورها است كه مهمترين مطالعه در

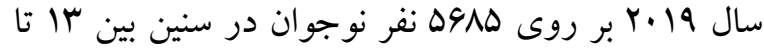
19 سال بوده كه طى آن مصرف الكل توسط يكى از والدين به عنوان ريسك فاكتور اقدام به خود كشى فرزند

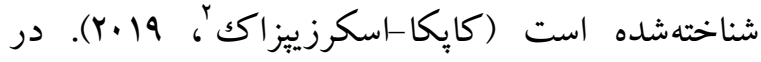
همين راستا بر اساس سيستماتيك ريويى كه در سال

2- Kapka-Skrzypczak, L., 2019
تعداد Y نفر مصرف الكل داشتند و ه P=• معنىدار

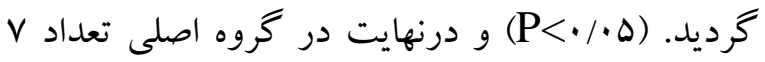
نفر و در كروه كنترل هيج كس مصرف مواد نداشت و

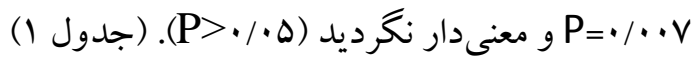
در زمان مصاحبه ازهر دو گروه اصلى و كنترل در مورد افكار فعال خودكشى در قالب زبرسشنامه 19 سؤالى خود كشى بك برسش هاى مربوطه مطرح كرديد. طبق جارجوب استاندارد اين يرسشنامه، در صورتى كه در باسخ به هؤ هوال ابتدايى، افكار خودكشى عنوان مى گرديد، نسبت به تكميل fl سؤال بعدى اقدام مىشد. بر اين اساس نتايج حاصله با توجه به برسشهاى مرتبط با افكار و رفتار خودكشى در آناليز نهايى 1 إيرسش، معنى

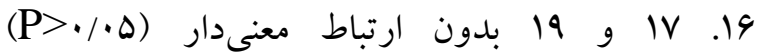

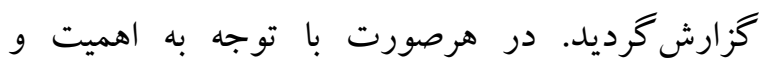
ارزشمندى ه سؤال اول برسشنامه بكك و معنىدار بودن هر هأ سؤل فوق در اين مطالعه، تفاوت معنىدار در خروههاى مورد و شاهد به دست آمده است. هدف از انجام اين مطالعه، بررسى رابطه مصرف انواع مواد، سيگار و الكل با اقدام به خود كشى در گروه سنى 4 تا 1 1 سال بود. مطالعات نشان دادهاند كه سوءمصرف الكل، تنباكو و مواد مخدر، خطر خودكشى را در نوجوانان افزايش مىدهد. مصرف الكل در نوجوانى، به خصوص شروع استفاده در يِش از نوجوانى، عامل خطر مهمى براى افكار خودكشى و اقدام به خودكشى در دختران و يسران نوجوان است (ينگك بيد و يلتزر '، .r.r.

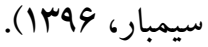

'- Pengpid, S., \& Peltzer, K., 2020 
مشخص بين مصرف سيگار با اقدام به خودكشى را بدست آوردند (يورالعجل و درويشى، هوسا). مصرف الكل در فرد مراجع در كروههاى اصلى و كنترل

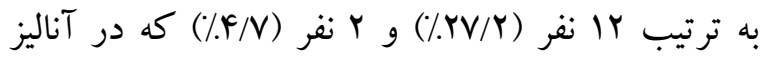
رابطه معنىدارى با خودكشى وى داشته است. بهطور مشابه در مطالعات متعددى در ساير كشورها اين رابطه مشخص گرديده است كه مىتوان به مطالعهاى كه در

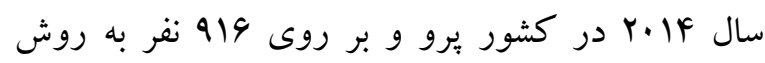
كراس سكشنال و با استفاده از برسشنامه و نيز مطالعهاى

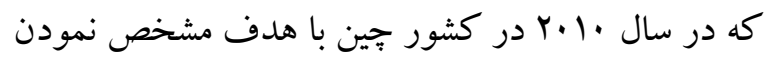
ريسك فاكتورهاى مرتبط با خود كشى انجام و اين ارتباط را مشخص نموده است، اشاره كرد (شارما، نام، كيم و كيمّ"، ها +Y). در همين زمينه در مطالعه بزركى كه بين بيش از ....سم نوجوان در سطح ه كشور آسياى جنوب

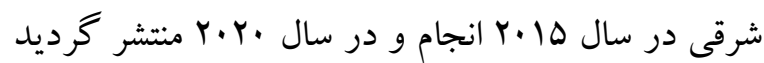
رابطه واضح بين اقدام به خود كشى با مصرف فعلى الكل ونيز مصرف طولانى مدت آمفتامينها و كانابيس مشخص بـ بـ كرديده است. بررسى مشابهى به روش متآناليز با بهره كيرى از هوه مطالعه انجام كه تأثير مستقيم متامقتامين بر ايجاد اختلالات روانيزشكى ازجمله اقدام به خودكشى اثبات كرديده است (مككتين، لونگك، استاكينگز، هو، فولدز، لايين، كامينگ، آرونو گيرى،

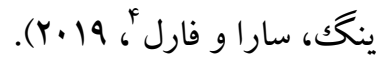

مصرف مواد مخدر اعم از ناركو تيككها و يا محر كها و

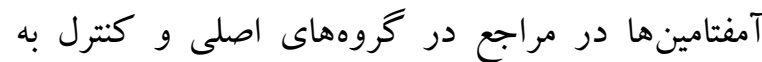
ترتيب V نفر (ه/Q/\%) و · نفر كه در آناليز رابطه

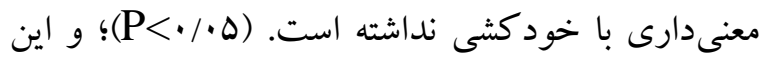

${ }^{3}$ - Sharma, B., Nam, E.W., Kim, H.Y. and Kim, J.K., 2015 4- McKetin, R., Leung, J., Stockings, E., Huo, Y., Foulds, J., Lappin, J.M., Cumming, C., Arunogiri, S., Young, J.T., Sara, G. and Farrell, M., 2019
انتشار و حاصل بررسى r.Y.r.

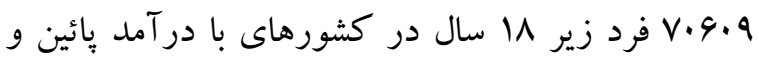
متوسط انجام گرديده مصرف خانوادگى الكل ارتباط مستقيمى با اختلالات رفتارى ازجمله سوءمصرف مواد ونيز الكل يافت شده است (جوكينن، الكساندر، مانيكام، هو گك، باتيل، بنجوما، داس و ديويدسون'، ·.Y.Y.). در اين مطالعه، مصرف مو اد مخدر اعم از ناركوتيككها و يا محرككها و آمفتامينها در بين بدران خانواده در

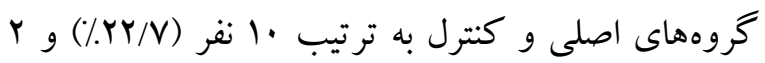

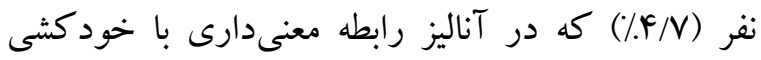
فرزند داشته است. (ه•/•>P)؛ كه همخام با مطالعهاى است كه در سال هوسا توسط بذرافشان و همكاران در دانشگاه علوم يزشكى شيراز انجام و اعتياد والدين با اقدام به خود كشى فرزند رابطه معنى دار داشته است (بذرافشان، شريف، ملازم و مانى، هوها). بين مصرف سيخار، قليان، الكل و انواع مواد مخدر توسط مادر و خود كشى فرزند رابطه معنىدارى يافت نشد. (ه•/P> P). شايد يكى از دلايل اين نتيجه تعداد كم مادران مصرف كننده در هر دو كروه اصلى و كنترل بوده است. مصرف سيگار در فرد مراجع در گرووهاى اصلى و كنترل

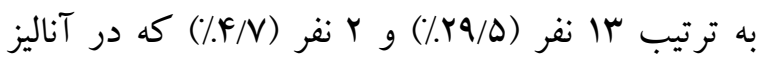
رابطه معنىدارى با خود كشى وى داشته است. (ه•/ P> P و در اين زمينه مشابه مطالعاتى كه در سال •. · ب در كشور جين با هدف مشخص نمودن ريسك فاكتورهاى مرتبط با افكار و نيز اقدام به خودكشى در يك دوره ماهه انجامشده و اين ارتباط را مشخص نموده است (جان

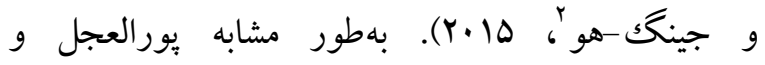
همكاران نيز با انجام متآناليز در به مطالعه ارتباط

1- Jokinen, T., Alexander, E.C., Manikam, L., Huq, T., Patil, P., Benjumea, D., Das, I. and Davidson, L.L., 2020

${ }^{2}$ - Juan W., 2015 
بررسى اقدام به خودكشى در سنين كودكى و نوجوانى

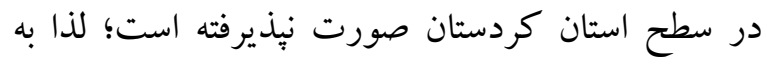
نظر مىرسد ضمن اينكه يافتهاى اين مطالعه مىتواند افت

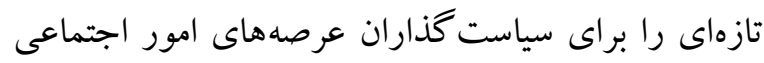
ونيز سلامت روان، آشكار ساخته تا با اين معضل بهعنوان يكك اختلال يا بيمارى قابل بيشگيرى برخورد نمايند. لازم است تا با برطرف نمودن نقايص اين بزوهش، نسبت به انجام مطالعه جامع تر اقدام نمود. يكى از مهمترين مشكلات بيشروى براى حساس سازى

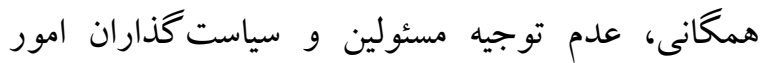
اجتماعى و حتى سلامت است و آمادهسازى ذهنى ايشان براى يذيرش واقعيتهاى موجود و برهيز از كوجى

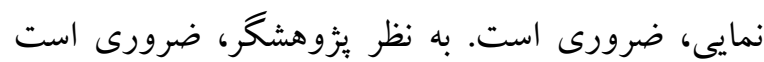
كه ديارتمان مستقلى تحت عنوان برنامه ملى بيشخيرى و مداخله در خودكشى كودكان و نوجوانان در ساختار وزارت بهداشت، درمان و آموزش بزشكى و بهتبع آن در

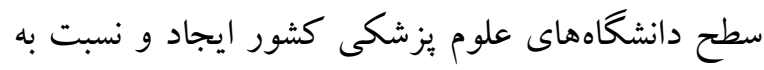
طراحى، برنامهريزى و اجرا در اين حوزه اقدام نمايد. نويسند كان بيشنهاد مىنمايند كه اولاً مطالعاتى در حجم إنى نمونه بيشتر و با لحاظ بررسى همهجانبه مسائل مرتبط و با لحاظ خصوصيات ويزه استان طراحى گردد و سامانهاى جهت ثبت و ضبط كليه موارد ارجاعى از سطح اول خدمات بهداشتى درمانى تا سطح بيمارستانى و يِيكيرى موارد جهت حصول درمان با هدف كاهش موارد تكرار خودكشى طراحى و و عملياتى گردد. اين مطالعه محدوديتهايى شامل عدم باور برخى از حوزههاى همكار به اهميت موضوع، دشوارى يذيرش خانوارها براى همكارى به خاطر ترس از عواقب احتمالى ثبت

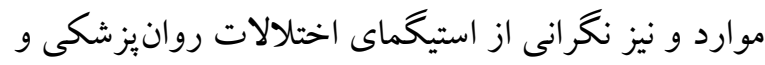

مورد برخلاف نتايج حاصله در مطالعهاى كه بهصورت متآناليز در سال هوبا انجام و علاوه بر نقش مستقيم مصرف مواد مخدر در اقدام به خودكشى، ميزان دوز مصرفى نيز بهعنوان عامل تقويتى آن شناخته شده است (:ور العجل، حق طلب، فرهادى و درويشى، هوسا). نكته قابل توجه اينكه در يكك مطالعه در كشور ايرلند در سال

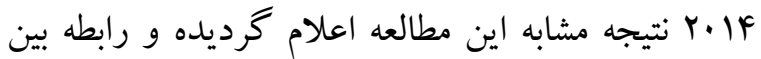
مصرف مواد و اقدام به خودكشى معنىدار نبوده است؛ ولى افكار خود كشى موجب تمايل فرد به مصرف برخى مواد ازجمله مارىجوانا بيان گرديده است (زانگك و وو'، .$(Y \cdot 1 F$ در زمان مصاحبه ازهر دو گرووه اصلى و كنترل، در مورد افكار فعال خودكشى در قالب برسشنامه 19 سؤالى خود كشى بكك، برسشهاى مربوطه مطرح كرديد؛ كه در

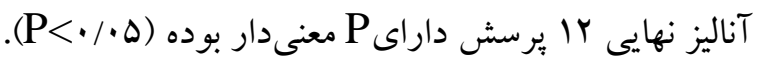
با توجه به اهميت و ارزشمندى ه سؤال اول برسشنامه بك و معنىدار بودن هر ه سؤال فوق در اين مطالعه، تفاوت معنى است.

\section{نتيجه كيرى}

بر اساس اين مطالعه، رابطه مصرف سيگار، انواع مواد و الكل به عنوان هردو عامل ريسك فاكتور و همبودى با اقدام به خود كشى مورد بررسى قرار گرفت كه مصرف سيخار، الكل و مواد مخدر در بين بدران خانواده و نيز مصرف سيگار و الكل توسط شخص كودك و نوجوان از ريسك فاكتورهاى معنىدار مرتبط با اقدام به خود كشى بودند. از آنجا كه تاكنون مطالعه منسجمى براى

${ }^{1}$ - Zhang, X. and Wu, L.T., 2014 
tendencies and suicide attempts in young people aged 13-19 years. Annals of agricultural and environmental medicine, 26(2), pp.329-336.

Khanipour H, Borjali A, \& Fasafinejad M. (2017). Nonsuicidal Self-injury in delinquent adolescents and adolescents with history of childhood maltreatment: motivation and suicide probability. Psychology of Exceptional Individual, 6(21), pp.60-79. (In Persian)

Kliem S, Lohmann A, Moble T, \& Brahler E. (2017). German Beck scale for suicide ideation (BSS): psychometric properties from a representative population survey. BMC psychiatry, 17(1), p.389.

McKetin R, Leung J, Stockings E, Huo Y, Foulds J, Lappin JM, Cumming C, Arunogiri S, Young JT, Sara G, \& Farrell M. (2019). Mental health outcomes associated with the use of amphetamines: A systematic review and meta-analysis. EClinicalMedicine, 16, pp.8197.

Pengpid S, \& Peltzer K. (2020). Suicide attempt and associated factors among adolescents in five Southeast Asian countries in 2015. Crisis: The Journal of Crisis Intervention and Suicide Prevention.

Poorolajal J, \& Darvishi N. (2016). Smoking and suicide: a meta-analysis. PloS one, 11(7), p.e0156348. (In Persian)

Poorolajal J, Haghtalab T, Farhadi M, \& Darvishi N. (2016). Substance use disorder and risk of suicidal ideation, suicide attempt and suicide death: a meta-analysis. Journal of Public Health, 38(3), pp.e282-e291. (In Persian)

Randall JR, Doku D, Wilson ML, \& Peltzer K. (2014). Suicidal behaviour and related risk factors among school-aged youth in the Republic of Benin. PLoSone, 9(2), p.e88233.

Sadock BJ, Sadock VA, \& Ruiz P. (2015). Synopsis of psychiatry: behavioral sciences, clinical psychiatry. Wolters Kluwer.

Sharma B, Nam EW, Kim HY, \& Kim JK. (2015). Factors associated with suicidal ideation and suicide attempt among school-going urban adolescents in Peru. International journal of

$$
\begin{aligned}
& \text { عدم دسترسى به اطلاعات حوزههاى مرتبط ديخر ازجمله } \\
& \text { بزشكى قانونى داشته كه لازم است تا در مطالعات آتى } \\
& \text { براى رفع يا كاهش آنها اقدام گردد. } \\
& \text { سياسگز ارى } \\
& \text { اين يزوهش بر اساس مصوبه شماره } \\
& \text { اخلاق IR.MUK.REC.1397/333 انجام و بدين } \\
& \text { وسيله نويسند گان مراتب سياس و تشكر خود را از گروه } \\
& \text { روانيزشكى، مركز تحقيقات علوم و اعصاب، گروه آمار } \\
& \text { و اييدميولوزى دانشگاه علوم بزشكى كردستان كه در } \\
& \text { مراحل مختلف اجراى اين يُزوهش ياريخر يزوهشخران } \\
& \text { بودند اعلام مىنمايند. }
\end{aligned}
$$

\section{References}

Bazrafshan MR, Sharif F, Molazem Z, \& Mani A. (2016). The effect of paternal addiction on adolescent suicide attempts: a qualitative study. Intemational joumal of high risk behaviors \& addiction, 5(3). (InPersian)

Esfahani M, Hashemi Y, \& Alavi K. (2015). Psychometric assessment of beck scale for suicidal ideation (BSSI) in general population in Tehran. Medical journal of the Islamic Republic of Iran, 29, p.268. (In Persian)

Jokinen T, Alexander EC, Manikam L, Huq T, Patil P, Benjumea D, Das I, \& Davidson LL. (2020). A systematic review of household and family alcohol use and adolescent behavioural outcomes in low-and middle-income countries. Child Psychiatry \& Human Development, pp.1-17.

Juan W, Jian-Xiong D, Lan G, Yuan H, Xue G, JingHui H, Guo-Liang H, \& Ci-Yong L. (2015). Non-medical use of psychoactive drugs in relation to suicide tendencies among Chinese adolescents. Addictive behaviors, 51, pp.3137.

Kapka-Skrzypczak L. (2019). Prevalence and selected risk factors of suicidal ideation, suicidal 
environmental research and public health, 12(11), pp.14842-14856.

Simbar M, Golezar S, Alizadeh S, \& Hajifoghaha M. (2018). Suicide Risk Factors in Adolescents Worldwide: A Narrative Review. Journal of Rafsanjan University of Medical Sciences, 16(12), pp.1153-1168. (InPersian)

Wang PW, \& Yen CF. (2017). Adolescent substance use behavior and suicidal behavior for boys and girls: a cross-sectional study by latent analysis approach. BMC psychiatry, 17(1), p.392.

Zhang X, \& Wu LT. (2014). Suicidal ideation and substance use among adolescents and young adults: A bidirectional relation?. Drug and alcohol dependence, 142, pp.63-73. 